\title{
ОБЗОР СХЕМ ТРЕХФАЗНЫХ АКТИВНЫХ ВЫПРЯМИТЕЛЕЙ С КОРРЕКЦИЕЙ КОЭФФИЦИЕНТА МОЩНОСТИ ДЛЯ ТЯГОВОЙ ПОДСТАНЦИИ ПОСТОЯННОГО TОКА
}

\author{
Асп. О.А. Плахтий \\ ОГЛЯД СХЕМ ТРИФАЗНИХ АКТИВНИХ ВИПРЯМЛЯЧІВ 3 КОРЕКЦЕЮ \\ КОЕФІЦЕНТА ПОТУЖНОСТІ ДЛЯ ТЯГОВОЇ ПІДСТАНЦІЇ ПОСТІЙНОГО \\ СТРУМУ
}

Асп. О.А. Плахтій

\section{THREE-PHASE ACTIVE RECTIFIERS WITH POWER FACTOR CORRECTION FOR DC TRACTION SUBSTATION}

\section{Postgraduate A. Plakhtiy}

В статье приведен обзор и сравнение схем активных выпрямителей, позволяюших реализовать коррекцию коэффициента мощңности и устранить высшие гармоники входного тока. Представлен ряд требований, исходя из которых была выбрана оптимальная схема трехфазного выпрямителя тяговой подстанщии, обеспечивающцая коррекцию коэффициента мошности.

Ключевые слова: трехфазный активный выпрялитель, коррекция коэффициента мощности, ККМ, тяговая подстанциия.

Діодні і тиристорні трифазні випрямлячі, застосовані на тягових підстанціях постійного струму, в ряді випадків не тільки не забезпечують можливість рекуперачї енергї, але також є потужним джерелом вищих гармонік загальнопромислової мережі, у зв'язку з чим є морально застарілими. Актуальним є пошук нових схемних рішень для випрямлячів тягової підстанції постійного струму. У статті наведено огляд схем активних випрямлячів з корекцією коефіиієнта потужності. Подано ряд вимог, виходячи з яких була обрана оптимальна схема для випрямляча тягової підстаниії.

Ключові слова: трифазний активний випрямляч, корекція коефіцієнта потужності, ККМ, тягова підстаниія.

The thyristor and diode three-phase rectifiers are used on the DC traction substations. These schemes have a number of drawbacks. In some cases, they do not provide the ability to recover energy, but also they are powerful source of current harmonic for general industrial electric grid. The presence of higher harmonics in power grid has the following negative consequences: distortion of the supply voltage; pickup in telecommunication and control circuits; heating and additional losses in transformers and electrical machines, which are powered from the power supply system; reducing the efficiency of the power supply system and technical devices. Basis of this, used schemes are outdated. The searching of new solutions for rectifying circuit installations traction substation is urgent. This article provides an overview of highly active rectifier circuits: the scheme of the three-phase active rectifier step-up, step-down circuit three-phase, active Viennarectifier, single-key scheme three-phase active rectifier. These schemes allows to implement the following options: power factor correction, sinusoidal input current, eliminating harmonic in input 
current, regulation of the output voltage of the rectifier, energy recovery in the network. The article presents the optimal scheme for the rectifier traction substation.

Keywords: three-phase active boost rectifier, power factor correction, PFC, DC traction substation.

Введение. На тяговых подстанциях постоянного тока применяются диодные и тиристорные трехфазные выпрямители. Данные схемы обладают рядом недостатков. В ряде случаев они не только не обеспечивают возможность рекуперации энергии, обладают низким коэффициентом мощности, но также являются мощным источником высших гармонических составляющих тока в общепромышленную сеть. Наличие высших гармоник тока в электросети несет следующие негативные последствия: искажение формы питающего напряжения; наводки в телекоммуникационных и управляющих цепях, снижение КПД самой системы электроснабжения и питающихся от нее технических устройств. В связи с этим применяемые схемы являются морально устаревшими. Актуальным является поиск путей модернизации выпрямительных установок тяговых подстанций [1].

\section{Целью данного исследования} является анализ возможности применения схем активных трехфазных выпрямителей с коррекцией коэффициента мощности на тяговых подстанциях постоянного тока.

Tрехфазный активный полномосто-
вой повышающий выпрямитель.
$\begin{array}{llll}\text { Существуют различные топологии } & \text { схем } \\ \text { активных выпрямителей } & \text { (далее } & \mathrm{AB} \text { ), }\end{array}$
обеспечивающие коррекцию коэффициента мощности. Одной из наиболее хорошо зарекомендовавших себя схем, имеющей высокие энергетические показатели, является схема активного полномостового повышающего выпрямителя [2]. Данная схема обеспечивает реализуемый коэффициент мощности, близкий единице, режим работы непрерывных токов и возможность реализации двунаправленного потока энергии, т.е. возможность рекуперации. Схема активного повышающего выпрямителя представлена на рис. 1. Форма входного напряжения и тока представлена на рис. 2.

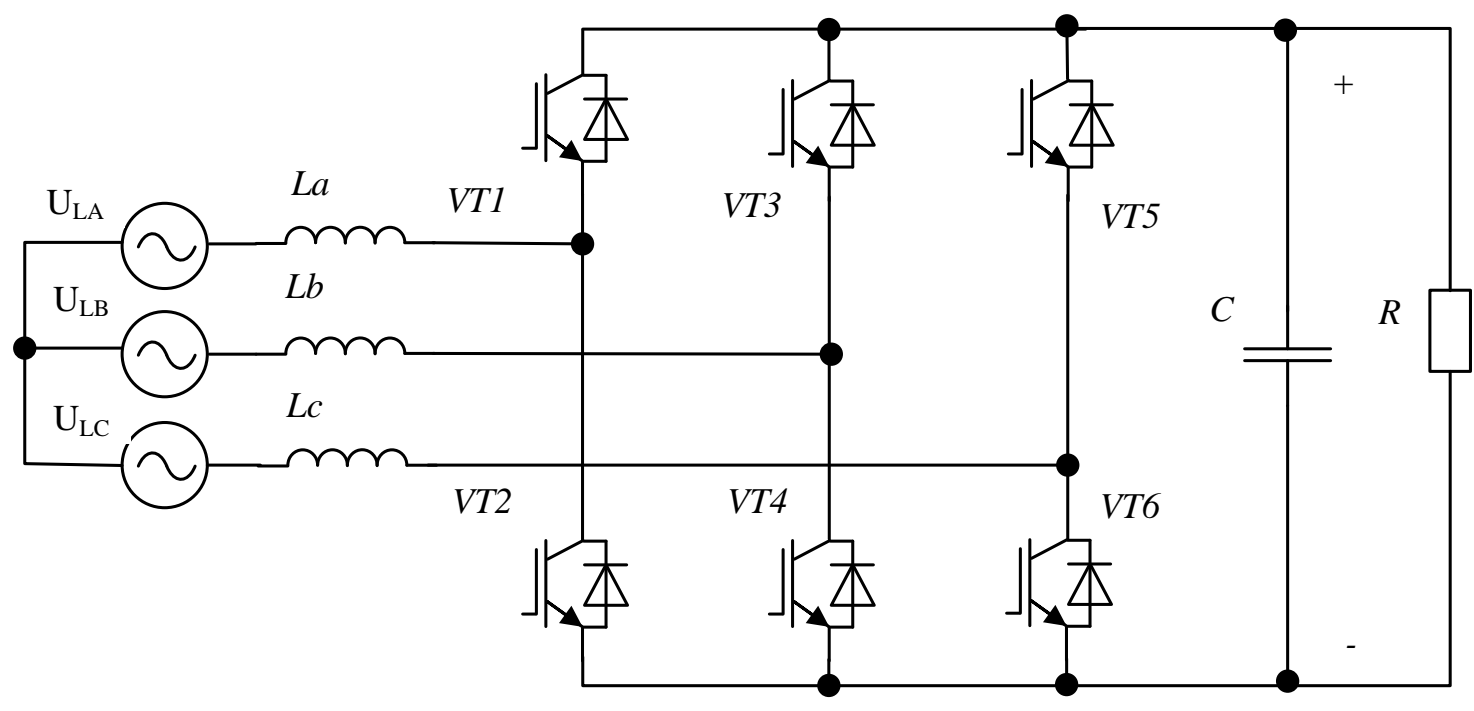

Рис. 1. Активный повышающий выпрямитель с коррекцией коэффициента мощности 


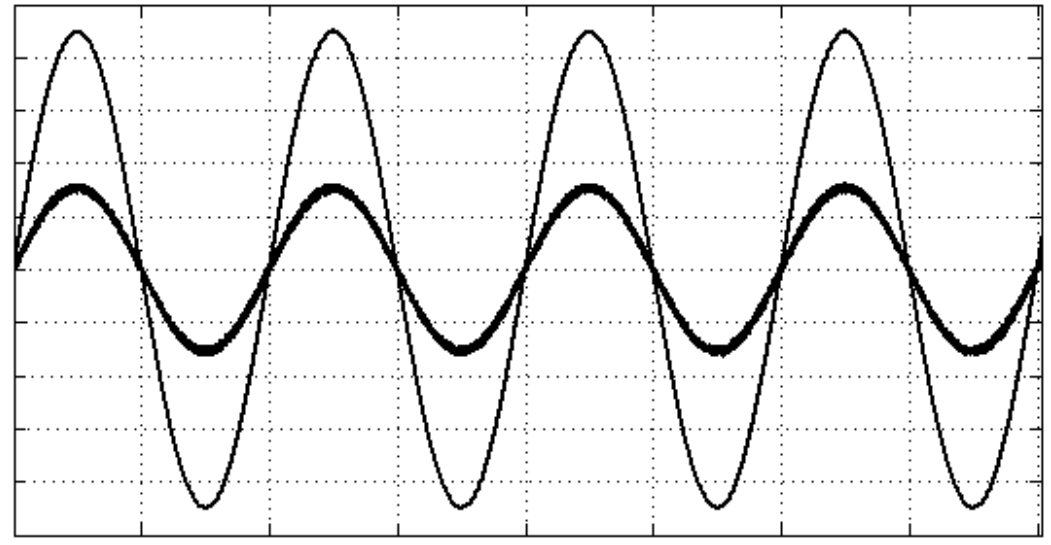

Рис. 2. Форма входного напряжения и тока фазы повышающего полномостового АВ

В состав данного преобразователя входит шесть полностью управляемых ключей типа IGBT. Обязательным условием возможности реализации синусоидальной формы входного тока выпрямителя является поддержание выходного напряжения преобразователя выше входного фазного напряжения активного выпрямителя. Отсутствие высших гармонических составляющих входного тока приводит к возможности значительного уменьшения входного ЭМС фильтра.

Недостатком схемы является необходимость использовать шесть активных ключей для обеспечения коэффициента мощности, близкого единице, когда, например, в схеме Виенна необходимо всего лишь три ключа, а в одноключевой схеме соответственно только один. Кроме того, в связи с тем, что схема по определению является повышающей, нет возможности регулирования выходного напряжения в диапазоне от нуля до значения амплитуды фазного напряжения.

\section{Активный}

полномостовой

понижающий выпрямитель. Трехфазный активный понижающий выпрямитель изображен на рис. 3. Преобразователь имеет возможность регулирования выходного напряжения в диапазоне от нуля до номинального значения сети, обеспечивая при этом синусоидальную форму входного тока и коэффициент мощности, близкий к единице.

Трехфазная понижающая схема может передавать мощность в нагрузку звена постоянного тока с незначительными (пренебрежительно малыми) искажениями входных токов, т.е. форма входных токов практически синусоидальна и схожа с формой повышающего выпрямителя, изображенной на рис. 2.

Данный преобразователь имеет регулируемое значение выходного напряжения в диапазоне от нуля до значения амплитуды фазного напряжения сети. Для корректной работы преобразователя необходимы двухквадрантные биполярные ключи, что хорошо реализуется последовательным соединением IGBT транзистора и силового диода. Недостатком данной схемы являются более высокие удельные потери в вентилях по сравнению с повышающим выпрямителем, обусловленные более высоким среднеквадратичным значением токов при последовательном соединении IGBT и диода, a также отсутствие возможности регулирования выходного напряжения выше фазного напряжения сети. Преобразователь способен работать в инверторном режиме, т.е. также обеспечивает возможность рекуперации. Однако рекуперация в данном типе преобразователя возможна только при обратной (отрицательной) полярности 
выходного напряжения, что делает применение еe на тяговой подстанции невозможной без дополнительных силовых устройств смены полярности.

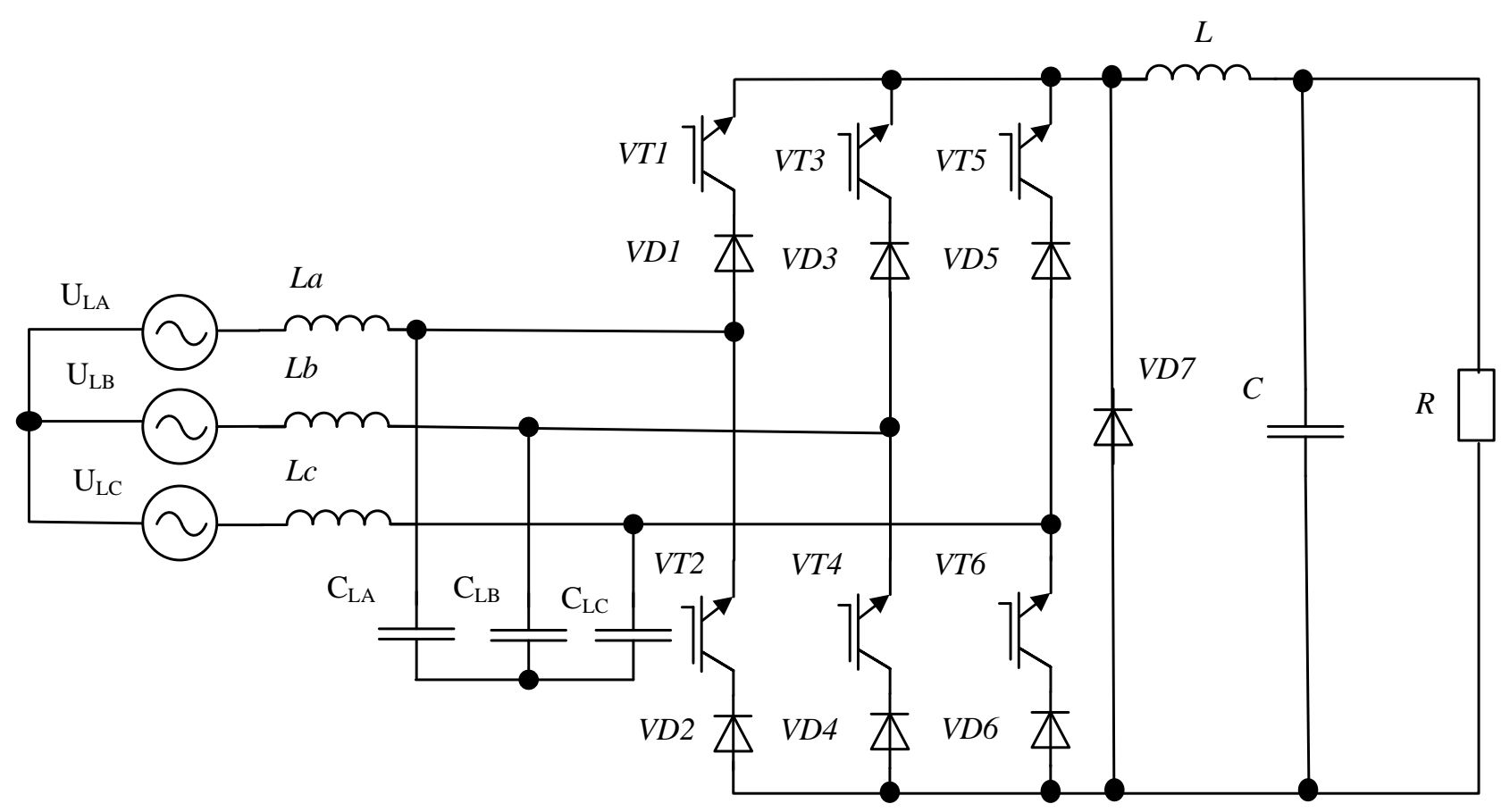

Рис. 3. Активный полномостовой понижающий выпрямитель

Виенна-выпрямитель. На данном этапе одной из наиболее изученных трехфазных схем коррекции коэффициента мощности является схема Виеннавыпрямителя [3]. Схема представлена на рис. 4.

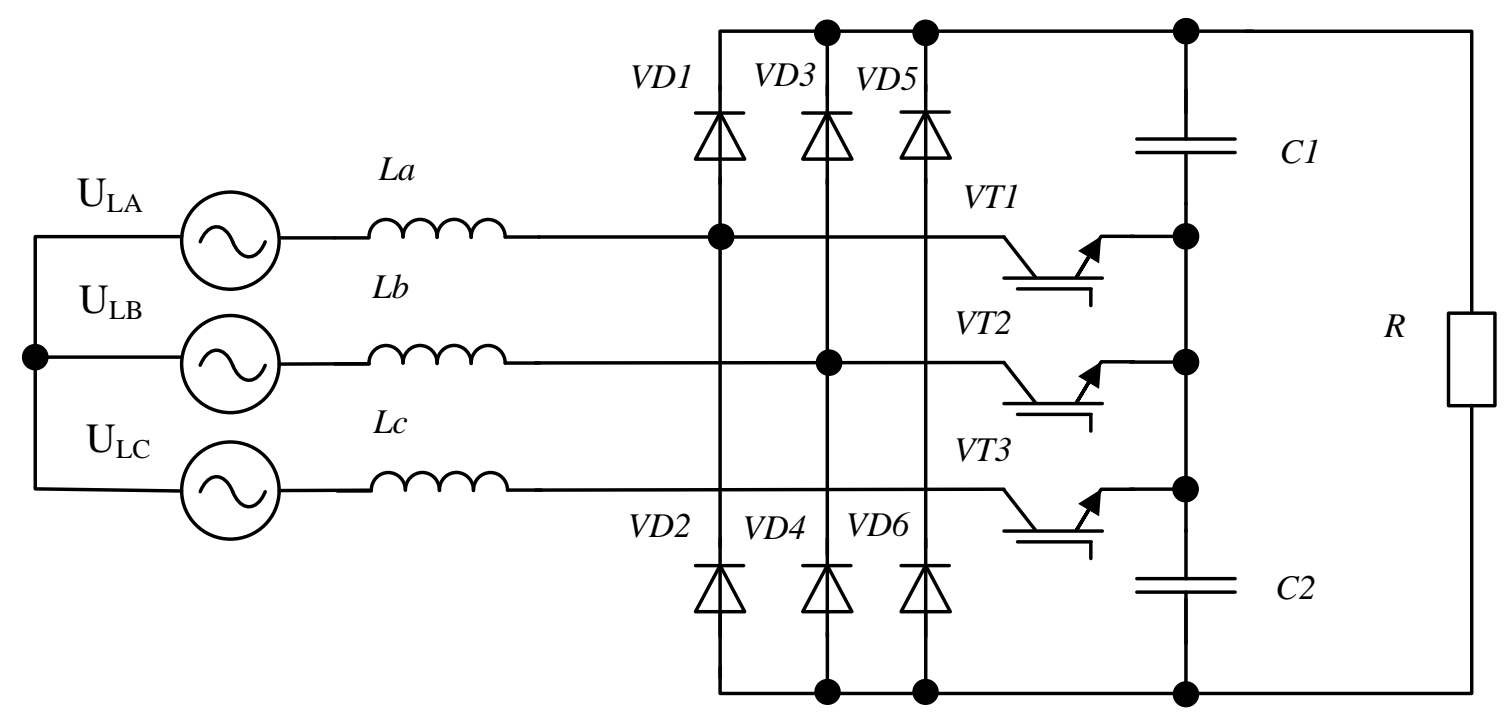

Рис. 4. Схема Виенна-выпрямителя 
Регулирование

выходного

напряжения происходит в диапазоне выше номинального значения напряжения сети, при этом реализуется синусоидальная форма входного тока и коэффициент мощности, близкий к единице. Преобразователь работает в режиме беспрерывных токов и имеет форму фазного тока, схожую с полномостовыми схемами, изображенную на рис. 2 . Достоинством данной схемы является уменьшенное количество силовых ключей в сравнении с полномостовыми схемами. Напряжение, приложенное к ключу, равно половине выходного, что дает возможность применения ключей низшего класса, имеющих соответственно более низкую стоимость. Недостатком схемы является отсутствие возможности реализации рекуперации.

\section{Одноключевой} трехфазный

активный выпрямитель. В виду того, что полностью управляемые силовые ключи являются достаточно дорогостоящими, стоит вопрос реализации активного выпрямителя с коррекцией коэффициента мощности с минимальным количеством активных ключей. $\mathrm{B}$ случае, когда необходимо уменьшить входные фильтры и реализовать активную коррекцию мощности, возможна реализация АВ всего с одним активным ключем [4]. Схема одноключевого повышающего $\mathrm{AB}$ представлена на рис. 5. Схема имеет регулирование уровня выходного напряжения выше значения напряжения сети и не обеспечивает возможности применения рекуперации.

Индуктивности La, Lb и Lc работают в режиме прерывистых токов в связке с диодами D1-D6. В конце интервала нарастания тока в дросселе ток достигает своего пикового значения, которое также пропорционально приложенному напряжению трехфазной сети. Когда транзистор Q1 запирается, то диод D7 становится прямосмещенным и дроссели передают накопленную в них энергию в нагрузку. Так как пик входных токов пропорционален амплитуде линейного напряжения, то среднее значение входных токов также приблизительно пропорционально значению линейного напряжения сети. Форма входного тока одноключевого повышающего $\mathrm{AB}$ представлена на рис. 6.

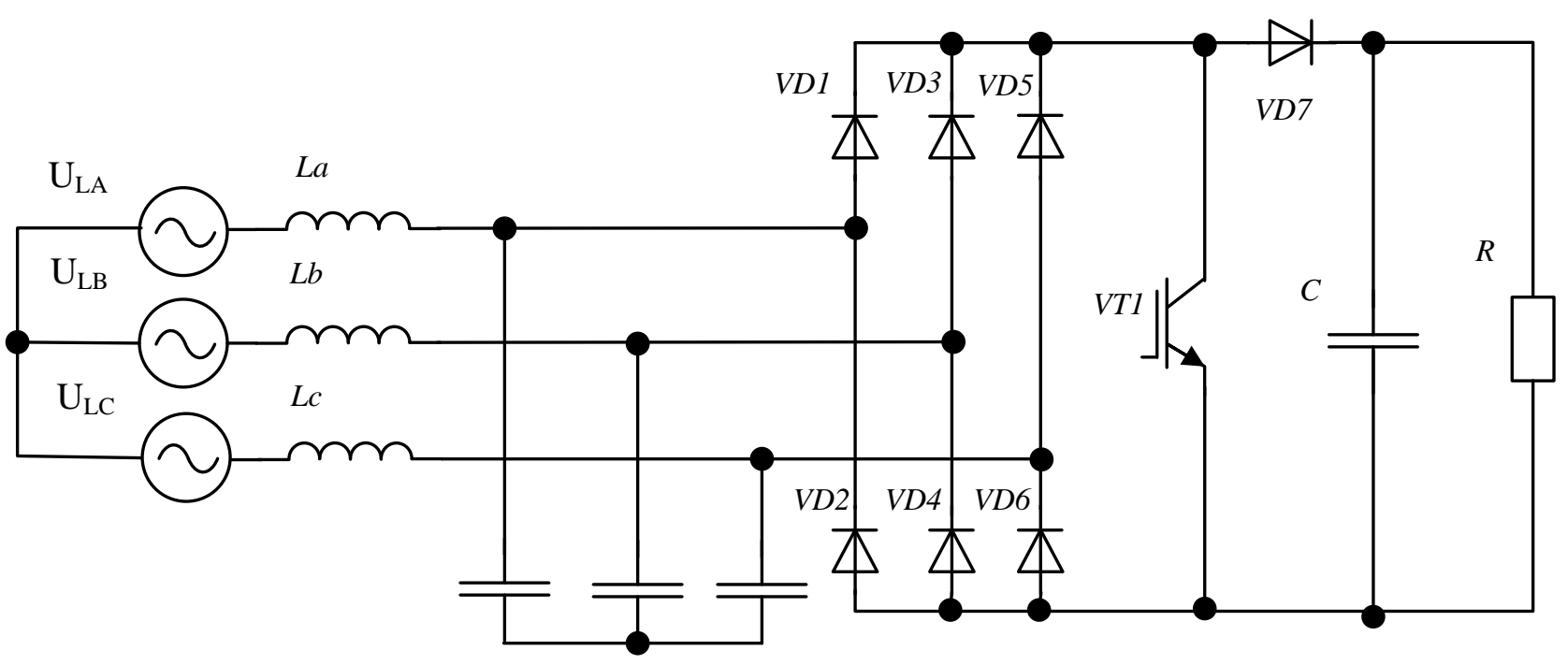

Рис. 5. Одноключевая схема повышающего активного выпрямителя 


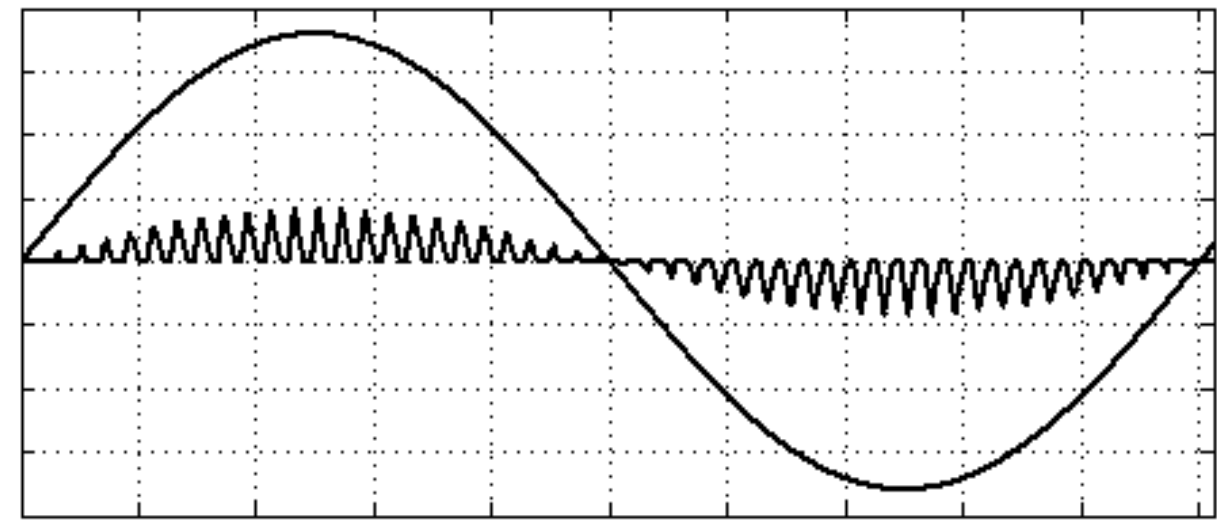

Рис. 6. Форма входного напряжения и тока фазы одноключевого повышающего АВ

Преобразователь имеет достаточно высокое содержание высших гармоник, но их количество, как и общий коэффициент гармонических искажений формы тока может быть уменьшен при дополнительном применении реактивных фильтров.

Сравнительный анализ схем коррекции мощности. Для выбора оптимальной схемы выпрямительного агрегата тяговой подстанции представлен ряд критериев: поддержание выходного напряжения 3,3 кВ в широком диапазоне нагрузок (от десятков ампер до нескольких килоампер), возможность реализации рекуперации энергии, реализация коэффициента мощности, близкого единице, минимальное содержание высших гармоник потребляемого тока.

Сводные характеристики схем активных выпрямителей представлены в таблице.

Одноключевая схема АВ оптимальна для реализации активных выпрямителей малой и средней мощности без рекуперации. Связано это с высокими удельными и пиковыми нагрузками ключа, и при реализации высокомощного выпрямительного агрегата мощностью порядка нескольких мегаватт исполнение одноключевой схемы является недопустимой.

Схема Виенна-выпрямителя обладает высокими энергетическими характеристиками, обеспечивает коэффициент мощности, близкий к единице, и оптимальна в качестве активного выпрямителя тяговой подстанции без необходимости рекуперации энергии.

Полномостовая понижающая схема $\mathrm{AB}$ для реализации рекуперации требует смены полярности выходного напряжения, что обуславливает необходимость дополнительных выходных устройств, чем проигрывает полномостовой повышающей схеме.

Полномостовая повышающая схема AB отвечает всем вышепоставленным требованиям: обеспечивает коэффициент мощности, близкий к единице, низкое содержание высших гармоник сети и является оптимальной схемой активного выпрямителя тяговой подстанции.

Вывод. В статье представлен анализ современных схем активных трехфазных выпрямителей с коррекцией коэффициента мощности. Оптимальной схемой АВ для тяговой подстанции постоянного тока с реализацией рекуперации является схема активного трехфазного полномостового повышающего выпрямителя. В случае, если реализация рекуперации не является необходимой, оптимальной схемой является схема Виенна-выпрямителя.

В дальнейшем необходимыми являются исследования систем управления данными преобразователями в условиях динамических изменений нагрузки и искажений питающей сети. 
Параметры схем активных трехфазных выпрямителей

\begin{tabular}{|c|c|c|c|c|}
\hline Параметр & $\begin{array}{c}\text { Полномостовая } \\
\text { повышающая } \\
\text { схема АВ }\end{array}$ & $\begin{array}{c}\text { Полномостовая } \\
\text { понижающая } \\
\text { схема АВ }\end{array}$ & $\begin{array}{c}\text { Схема Виенна- } \\
\text { выпрямителя }\end{array}$ & $\begin{array}{c}\text { Одноключевая } \\
\text { схема AB }\end{array}$ \\
\hline $\begin{array}{c}\text { Выходное } \\
\text { напряжение В }\end{array}$ & Выше $\mathrm{U}_{\mathrm{L}}^{*}$ & Ниже $\mathrm{U}_{\mathrm{L}}{ }^{*}$ & Выше $\mathrm{UL}_{\mathrm{L}}^{*}$ & Выше $\mathrm{UL}_{\mathrm{L}}^{*}$ \\
\hline $\begin{array}{c}\text { Напряжение на } \\
\text { ключе, В }\end{array}$ & $\mathrm{U}_{\text {вых }}$ & $\mathrm{U}_{\text {Bых }}$ & $\mathrm{U}_{\text {вых }} / 2$ & $\mathrm{U}_{\text {вых }}$ \\
\hline $\begin{array}{l}\text { Возможность } \\
\text { рекуперации }\end{array}$ & Есть & $\begin{array}{c}\text { При смене } \\
\text { полярности Uвых }\end{array}$ & нет & нет \\
\hline $\begin{array}{c}\text { Напряжение на } \\
\text { конденсаторах } \\
\text { фильтра, В }\end{array}$ & $\mathrm{U}_{\text {вых }}$ & $\mathrm{U}_{\mathrm{BbI}}$ & $\mathrm{U}_{\text {вых }} / 2$ & $\mathrm{U}_{\text {BыX }}$ \\
\hline $\begin{array}{c}\text { Количество } \\
\text { полностью } \\
\text { управляемых } \\
\text { ключей }\end{array}$ & 6 & 6 & 3 & 1 \\
\hline $\begin{array}{c}\text { Количество } \\
\text { диодов }\end{array}$ & 6 & 6 & 6 & 7 \\
\hline $\begin{array}{c}\text { Коэффициент } \\
\text { мощности }\end{array}$ & $0,98-0,99$ & $0,92-0,98$ & $0,98-0,99$ & 0,73 \\
\hline $\operatorname{Cos} \varphi$ & $0,99-1$ & $0,99-1$ & $0,99-1$ & $0,98-1$ \\
\hline $\begin{array}{c}\text { Коэффициент } \\
\text { гармонических } \\
\text { искажений } \\
\text { формы тока THD }\end{array}$ & $3-12 \%$ & $3-12 \%$ & $3-12 \%$ & $60-90 \%$ \\
\hline
\end{tabular}

* $\mathrm{U}_{\mathrm{L}}-$ входное фазное напряжение $\mathrm{AB}$.

\section{Список использованных источников}

1. Горячев, В.Я. Основные способы управления параметрами энергетических систем для снижения влияния нелинейных загрузок на показатели качества электрической энергии [Текст] / В.Я. Горячев, Д.А. Кузьмин, Н.Б. Джазовский // Современные проблемы науки и образования. - 2012. - №6. - C.23-31.

2. H. Mao. Analysis and Design of a High Frequency Three-Phase Boost Rectifier [Текст] / H. Mao, D. Boroyevich, A. Ravindra, F. Lee // IEEE Applied Power Electronics Conference, 1996 Record, C. 538-544.

3. Чаплыгин Е.Е. Виенна-выпрямитель - трехфазный корректор коэффициента мощности [Текст] / Е.Е. Чаплыгин, Во Минь Тьинь, Нгуен Хоанг Ан // Силовая электроника (приложение к журналу «Компоненты и технологии»). - 2006. - №1. - С. 20-23.

4. Ghanemm, M. A. New single phase buck-boost converter with unity power factor [Текст] / Ghanemm, M., Haddas, K.A, and Ray, G // IEEE APEC, 1993, P. 785-792.

Рецензент д-р техн. наук, профессор Я.В.Щербак

Плахтій Олександр Андрійович, аспірант кафедри автоматизованих систем електротранспорту Української державної академії залізничного транспорту. Тел.: (057)730-10-73. E-mail: 83et@ mail.ru.

Plahty Alexander A., postgraduate department automated electric Ukrainian State Academy of Railway Transport. Tel.: (057) 730-10-73. E-mail: 83et@mail.ru. 